\title{
Article \\ Optimizing Stock Market Returns during Global Pandemic Using Regression in the Context of Indian Stock Market
}

\author{
Pradip Debnath ${ }^{1, *(D)}$ and Hari Mohan Srivastava $2,3,4,5, *$ (D) \\ 1 Department of Applied Science and Humanities, Assam University, Cachar, Assam, Silchar 788011, India \\ 2 Department of Mathematics and Statistics, University of Victoria, Victoria, BC V8W 3R4, Canada \\ 3 Department of Medical Research, China Medical University Hospital, China Medical University, \\ Taichung 40402, Taiwan \\ 4 Department of Mathematics and Informatics, AzerbaiJanuary University, 71 Jeyhun Hajibeyli Street, \\ Baku AZ1007, Azerbaijan \\ 5 Section of Mathematics, International Telematic University Uninettuno, I-00186 Rome, Italy \\ * Correspondence: debnath.pradip@yahoo.com (P.D.); harimsri@math.uvic.ca (H.M.S.)
}

Citation: Debnath, Pradip, and Hari Mohan Srivastava. 2021. Optimizing Stock Market Returns during Global Pandemic Using Regression in the Context of Indian Stock Market. Journal of Risk and Financial Management 14: 386. https:// doi.org/10.3390/jrfm14080386

Academic Editor: Kim Hiang Liow

Received: 11 July 2021

Accepted: 17 August 2021

Published: 19 August 2021

Publisher's Note: MDPI stays neutral with regard to jurisdictional claims in published maps and institutional affiliations.

Copyright: (c) 2021 by the authors. Licensee MDPI, Basel, Switzerland. This article is an open access article distributed under the terms and conditions of the Creative Commons Attribution (CC BY) license (https:// creativecommons.org/licenses/by/ $4.0 /)$.

\begin{abstract}
Stock markets around the world experienced a massive collapse during the first wave of COVID-19. Roughly in the month of January 2021, the second wave of COVID-19 struck in India, reaching its peak in May, and by the end of May, the active cases started to decline. A third wave is again predicted by the end of 2021, and as such, the COVID-19 pandemic seems to have become a periodic phenomenon over the last couple of years. Therefore, the study of the behavior of the stock market as well as that of the investors becomes very interesting and crucial in this highly volatile and vulnerable market trend. Motivated by these facts, in the present paper, the researcher develops a model for portfolio management, using curve-fitting techniques and shows that this model can encounter the market volatility efficiently in the context of the Indian stock market. The portfolio is designed based on data taken from the National Stock Exchange (NSE), India, during 1 January 2020 to 31 December 2020. The performance of the portfolio in real-life situation during 1 January 2021 to 21 May 2021 is examined, assuming investments are made according to the proposed model.
\end{abstract}

Keywords: stock prediction; regression; method of least squares; COVID-19; mutual fund; portfolio management

\section{Introduction}

The stock market behavior and its pattern have remained a mystery for mathematicians and scientists for decades. However, there has been a significant amount of successful studies for developing models for short-term prediction in the stock market (see the works of Gottschlich and Hinz (2014); Liao et al. (2012) and the references therein). Altay and Satman (2005) used an artificial neural network and linear regression for stock market forecasting. An interesting survey of stock market prediction was carried out by Atsalakis and Valavanis (2009), and Baralis et al. (2017) developed stock portfolios with the help of weighted frequent item sets.

The first wave of the COVID-19 pandemic ravaged the entire world's economy and hardly any country was prepared to tackle this devastating situation. As a result, the stock markets of each and every country experienced a sudden deep fall and many investors and retailers suffered huge losses. The impact of the COVID-19 pandemic on stock market returns has been and is being studied by scientists all over the world. For some noteworthy research in this vein, we refer to the works of (Al-Awadhi et al. 2020, 2021; Albulescu 2020; Dou et al. 2021; Engelhardt et al. 2020; Erdem 2020; Mazur et al. 2020; Rahman et al. 2021; Takahashi and Yamada 2020; Wilms et al. 2021; Zaremba et al. 2020; Zhang et al. 2020). 
Almost after a year, when the pandemic seemed to be in control, the economy started to get back on track. However, then, the second wave of COVID-19 hit and cast a cloud of uncertainty on the stock markets. In such a situation, the investors and retailers are very fearful and confused as to when and where to invest their funds. It therefore becomes very important and essential to develop some mathematical model, which can address these investment queries during a global crisis. The objective is to prepare for the worst case scenario and still stay invested and procure capital gains.

In this paper, we develop a portfolio consisting of five sectors, including pharmaceuticals, petroleum, bank, software (IT) and metal.

This research will help new as well as seasoned investors to manage their own portfolio and generate better returns than mutual funds. Roughly around only $4.5 \%$ of the population of India invests directly in the stock market as compared to $54 \%$ in the U.S.A. and $10 \%$ in China, as of 2020. Such low retail investment in India is partly because of the lack of financial awareness and partly because of the deep risk that stock market investment involves. Our aim is to build a sustainable portfolio consisting of fundamentally strong sectors and companies, which perform well, even in toughest time and minimize the risk of financial loss. At the same time, the retailers can limit their dependence on mutual funds.

\section{Methodology}

Our main objective in this research is to allocate the total fund into different wellperforming sectors and then allocate the sector-wise fund into fundamentally strong companies to maximize returns. In 2003, Rusu and Rusu (2003) suggested some efficient forecasting methods for stock market analysis, whereas a stock market portfolio recommender system was developed by Paranjape-Voditel and Deshpande (2013) in 2013. Recently, Maji et al. (2021) studied a portfolio management method by curve-fitting techniques. The methodology adopted in this research is developed on the basis of works in (Maji et al. 2021; Paranjape-Voditel and Deshpande 2013; Rusu and Rusu 2003).

We develop our model based on data from 1 January 2020 to 31 December 2020. We predict and compare our experimental results with popular mutual funds in the period of 1 January 2021 to 21 May 2021. The main reason for selecting such periods is to study the effect and impact of COVID-19 on stock market behavior and to create a portfolio that can encounter such global hazards and sustain in normal situations as well. In India, the first wave of COVID-19 hit the country in the month of January 2020 and started to decline by the end of the year. Hence, this period is considered to generate our initial data set. The second wave hit in the month of January 2021, reached its peak in April-May 2021 and started to decline at the end of May 2021. Thus, we use the period January-May 2021 for evaluation and comparison.

First, we find a curve of best fit for each of the companies by the method of least squares, using the data from 1 January 2020 to 31 December 2020. With the help of this best-fit curve, we predict the stock price closing value at the end of our evaluation and comparison period to justify the validity of our model. However, this prediction is crude, as we do not apply error estimation or correction.

Next, we cluster the top 4 companies within each sector with a positive growth rate in the specified period for diversified fund allocation. We cannot simply allocate all the funds to the top performing company or equally among all the companies. Hence, a mathematical formulation for the allocation is proposed.

Next, the growth rate of each company is calculated. Weights are set for the previous period stock prices. Further, the mean growth rates of the companies are calculated and then the net growth rate of all the sectors are obtained. The idea is to allocate a larger amount of funds to a sector with high growth and a lesser amount to the sectors next to it in terms of growth. 
Given below is the step-by-step formulation of our methodology:

- Cluster sector wise:

(i) Cluster list companies into different industry sectors manually.

(ii) Associate each company to the sector to which it belongs.

- Company growth estimate:

(i) Find the estimated growth rate of the company using historical data.

(ii) Rank all companies with a positive growth rate.

(iii) For each sector, consider the top 4 companies.

- Sector growth estimate:

(i) Find the mean growth rate of the top 4 companies in the sector.

(ii) Rank all sectors with a positive growth rate.

(iii) Top 5 sectors are considered for fund allocation.

- Fund allocation:

(i) Fund is allocated among the selected top 5 sectors, proportional to their average growth rate.

(ii) Each sector-wise fund is again divided among companies, proportional to their growth rate.

\section{Algorithm for Diversified Fund Allocation across Sectors and Companies}

In the proposed methodology, the prediction of the current stock price is done on the basis of data from previous $s$ months (in our case, $s=12$ ). The month-wise weight $\left(X_{i}\right)$ is used for predicting the stock price. It is to be mentioned that the weighting scheme uses linearly decreasing weights; the highest weight belongs to the last observation, the one preceding the value to be forecast. Then, $X_{1}$ with the smallest weight is the oldest observation. For the $i$-th month, it is calculated as follows:

$$
X_{i}=\frac{2 \times(s-i+1)}{s \times(s+1)} .
$$

The top performing sectors are identified by analyzing the results of these sectors from NSE web portal in the specified period. Top performing and fundamentally strong companies are then selected within each sector in a similar manner so that all companies are listed in the NIFTY 50 index during this period. All historical data of the stock prices were collected from the NSE (web portal: www.nseindia.com (accessed on 22 May 2021)).

We now present below the algorithm, step by step.

Step 1 Prediction of stock closing prices.

(a) Identifying the curve of best fit.

(i) Collect the historical data of stock closing prices of a company for the specified period of 12 months. This is the initial data set for our model.

(ii) Find the curve of best fit using the method of least squares for the collected 12 month data.

(iii) The curve of best fit is chosen for which the root mean square error (RMSE) is minimal.

(iv) Predict the stock closing price for the end of the comparison period (i.e., when we would be interested in withdrawing the fund-in this case, after 5 months) as decided in the model.

(v) Repeat steps (i)-(iv) for each of the selected companies. 
Step 2 Selection of companies within sectors.

(a) Choose a company from a particular sector.

(b) Find the percentages of the growth rate of the company of different time periods with respect to the month immediately prior. Suppose the growth rate between the $\mathrm{i}$-th previous month and $(i-1)$-th previous month is $p_{i}$, where $i=1$ to 12 . Thus, $p_{i}$ is the growth rate of the $(i-1)$-th time period with respect to the month immediately prior. Suppose that the growth rates of a company are $p_{1}, p_{2}, \ldots, p_{12}$ for the selected period of 12 months.

(c) Calculate company net growth rate (CNGR) by the following formula: $C N G R_{l}=X_{1} p_{1}+X_{2} p_{2}+\cdots+X_{12} p_{12}$, where $l=1$ to $m$ (for $m$ number of companies within each sector).

(d) Repeat steps (a)-(c) for each company within the sector.

(e) Consider only the companies having a positive growth rate and discard the ones with a negative growth rate.

(f) Calculate the net growth rate of a particular sector by finding the mean of the growth rates of the companies within the sector.

(g) Repeat all the steps of step 2 for each sector.

Step 3 Allocation of funds.

(a) Sector-wise.

(i) Find the sector multiplying factor (SMF) as follows: $S M F=\frac{100}{\sum_{i=1}^{n} G_{i}}$, where $G_{i}$ is the growth rate of sector $S_{i}$, and $n$ is the number of sectors (here $n=5$ ).

(ii) Find the sector-wise fund to be invested by the mathematical formula given by $S P_{i}=G_{i} \times S M F$, where $S A_{i}$ denotes sector-wise \% allocation. Thus, the sector-wise allocation is given by $S F_{i}=F \times S P_{i}$, where $F$ denotes the total fund.

(iii) Repeat steps (i)-(ii) for all the selected sectors.

(b) Company-wise: let each sector $S_{i}$ consist of $m$ number of companies $C_{1}, C_{2}, \ldots C_{m}$ with growth rates of $g_{1}, g_{2}, \ldots, g_{m}$ respectively.

(i) Determine the company multiplying factor (CMF) by the formula $C M F=\frac{100}{\sum_{i=1}^{m} g_{i}}$.

(ii) Find the company-wise fund allocation by the formula $C P_{i}=g_{i} \times C M F$ for company $C_{i}$, where $C P_{i}$ denotes company-wise allocation \%. Thus, company-wise allocation is given by $C F_{i}=S F_{i} \times C P_{i}$.

(iii) Repeat step (ii) for all the companies.

\section{Results and Discussion}

In our experiment, we have collected the historical data of closing stock prices for 20 companies from 5 different sectors ( 4 companies from each sector). These data were collected from NSE for each of the 20 companies between 1 January 2020 and 31 December 2020. Similar data from 1 January 2021 to 21 May 2021 were used for validation, evaluation and comparison of the proposed portfolio with the performance of other popular mutual funds.

In this research, the currency unit is Indian rupees (INR). For simplified calculations, we have considered our total fund as $F=$ INR 100,000. Such a fund will be useful for a new retail investor. Additionally, for a large fund, suitable scaling of this amount can be very easily done.

In our experiment, first we perform regression on every company's closing stock price from our initial data set and select the curve of best fit.

As an example, in Figure 1, we show the different trend lines fitted with the closing stock prices of Dr. Reddy's Lab (Pharma sector). 


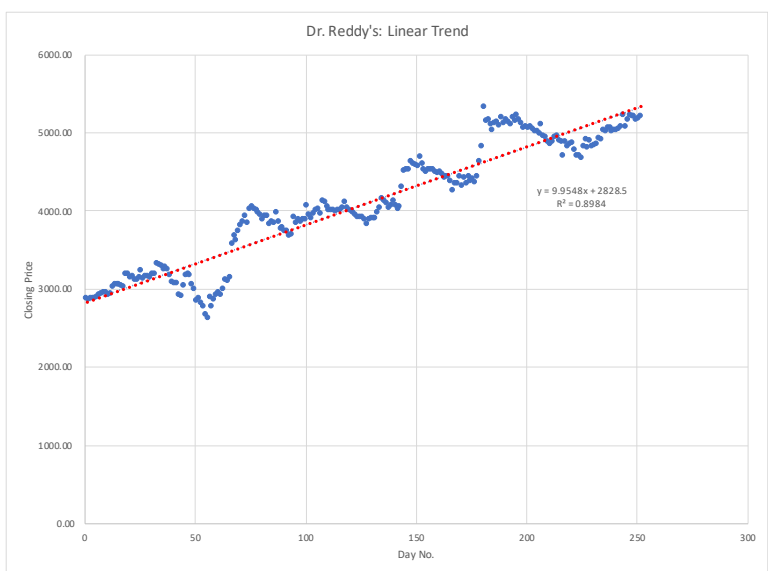

(a)

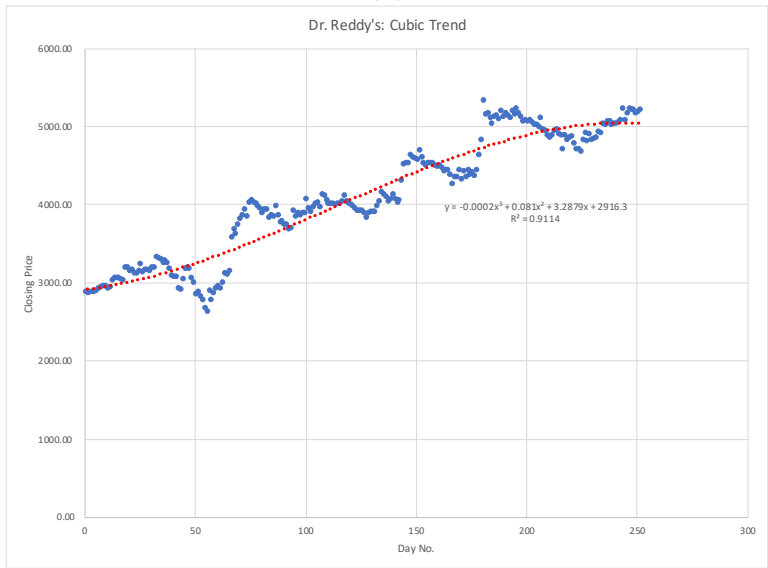

(c)

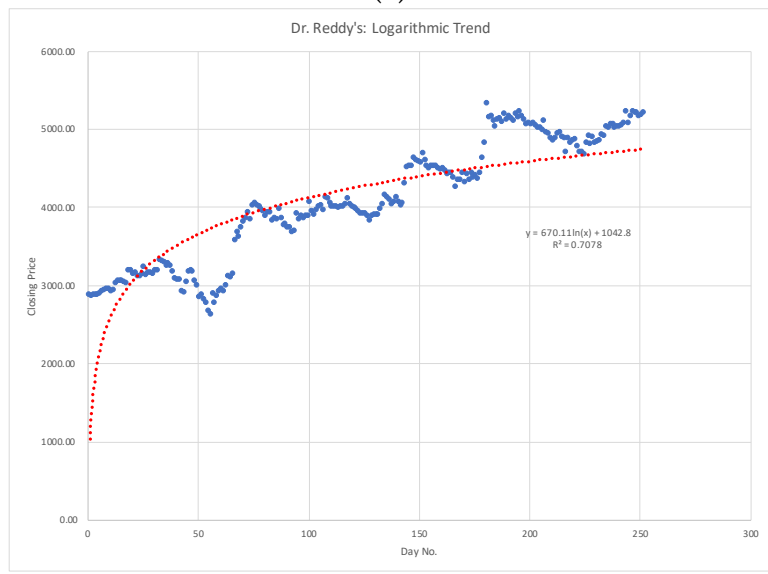

(e)

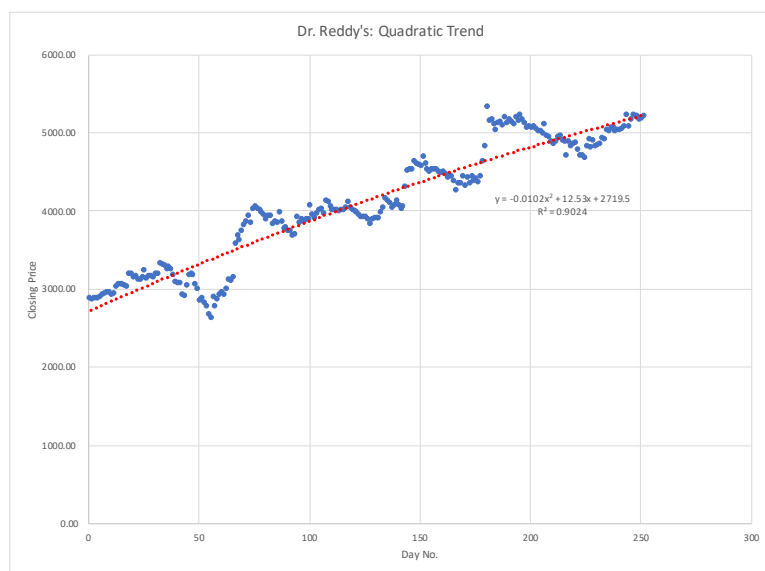

(b)

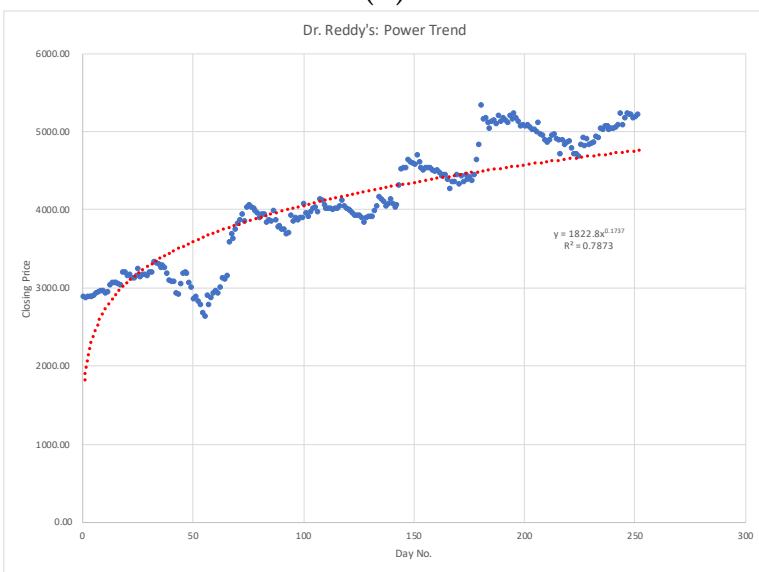

(d)

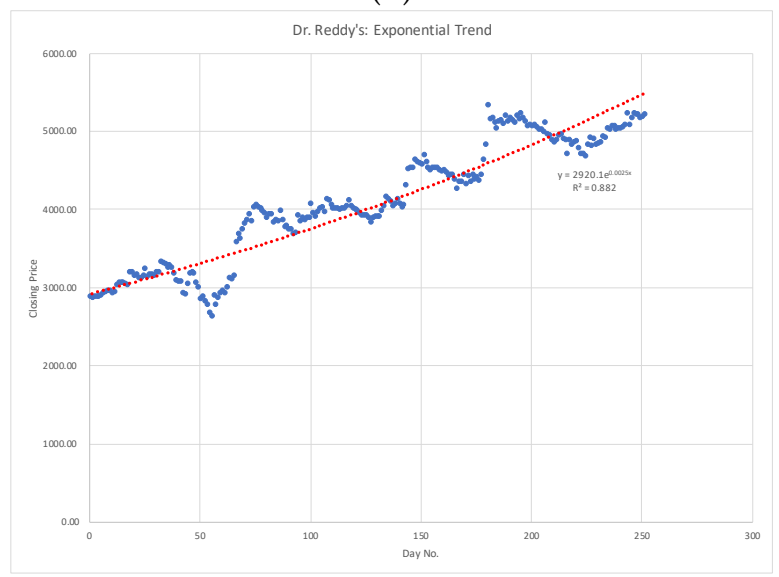

(f)

Figure 1. Trend lines for Dr. Reddy's Lab (Pharma Sector): January-December 2020.

The equation of the fitted trend line, R-squared error, RMS Error were calculated and are presented in Table 1. The same process was carried out for all the 20 companies, but for the sake of brevity, we display only one. 
Table 1. Best fit curve and RMSE for Dr. Reddy's Lab (Pharma sector).

\begin{tabular}{cccc}
\hline Curve Trend & Equation & R-Squared Error & RMS Error \\
\hline Linear & $9.9548 x+2828.5$ & 0.8984 & 243.5023 \\
Quadratic & $-0.0102 x^{2}+12.53 x+2719.5$ & 0.9024 & 238.6897 \\
Cubic & $-0.0002 x^{3}+0.081 x^{2}+3.2879 x+2916.3$ & 0.9114 & 334.6979 \\
Logarithmic & $670.11 \ln x+1042.8$ & 0.7078 & 412.9882 \\
Exponential & $2920.1 e^{0.0025 x}$ & 0.882 & 263.5039 \\
\hline
\end{tabular}

Our initial data are based on the closing stock price of all the selected companies from 1 January 2020 to 31 December 2020, which comprises a total of 252 working days in the Indian stock market. Further, our evaluation and comparison period for the experiment is from 1 January 2021 to 21 May 2021, which comprises 94 days. Thus, we find our predicted stock price for the 346th day $(252+92=346)$ using regression. The best fit curve for each company along with its CNGR and predicted stock price are listed in Table 2.

Table 2. Curve of best fit and CNGR of the companies.

\begin{tabular}{|c|c|c|c|c|c|c|}
\hline S1. No. & Sector & Company Name & Curve of Best Fit & CNGR & $\begin{array}{c}\text { Predicted } \\
\text { Stock Price on } \\
21.05 .2120\end{array}$ & $\begin{array}{c}\text { Actual Stock } \\
\text { Price on } \\
21.05 .2021\end{array}$ \\
\hline 1 & Pharma & Dr. Reddy's Lab & Quadratic & 4.30124 & 5833.77 & 5216.45 \\
\hline 2 & Pharma & Sun Pharmaceuticals & Cubic & 2.6818 & 497.6 & 690.4 \\
\hline 3 & Pharma & Divi's Lab & Exponential & 2.1625 & 4863.2 & 4079.9 \\
\hline 4 & Pharma & Cipla & Cubic & 3.5268 & 1021.502 & 926.9 \\
\hline 5 & Software & Infosys & Cubic & 4.528 & 2376.92 & 1354.50 \\
\hline 6 & Software & TCS & Cubic & 2.534 & 2071.6 & 3080.5 \\
\hline 7 & Software & HCL & Quadratic & 3.24 & 2237.98 & 930.65 \\
\hline 8 & Software & Wipro & Cubic & 4.512 & 401.52 & 512.7 \\
\hline 9 & Petro & Reliance Ind. & Exponential & 5.2712 & 2888.44 & 2002.55 \\
\hline 10 & Petro & BPCL & Power & 2.1074 & 359.55 & 461.05 \\
\hline 11 & Petro & ONGC & Quadratic & 1.9271 & 151.58 & 112.75 \\
\hline 12 & Petro & Indian Oil Corp. & Cubic & 1.524 & 76.65 & 104.3 \\
\hline 13 & Bank & HDFC & Exponential & 4.109 & 1329.58 & 1497.3 \\
\hline 14 & Bank & ICICI & Exponential & 2.1034 & 556.42 & 642.45 \\
\hline 15 & Bank & Kotak Mahindra & Exponential & 2.5221 & 1626.84 & 1757.65 \\
\hline 16 & Bank & SBI & Power & 4.212 & 184.66 & 401.2 \\
\hline 17 & Metal & Hindalco & Power & 2.014 & 251.2 & 389.8 \\
\hline 18 & Metal & SAIL & Quadratic & 2.84 & 59.8 & 122.0 \\
\hline 19 & Metal & Tata Steel & Exponential & 3.1244 & 765.32 & 1113.1 \\
\hline 20 & Metal & Hindustan Zinc & Exponential & 2.0127 & 251.32 & 344.55 \\
\hline
\end{tabular}

Next, we perform the allocation of funds into multiple sectors by taking the mean of CNGR computed in Table 2 for each sector. This allocation is presented in Table 3.

Table 3. Sector-wise fund allocation.

\begin{tabular}{ccccc}
\hline S1. No. & Sector & $\begin{array}{c}\text { Sector } \\
\text { Growth Rate } \\
\left(G_{i}\right)\end{array}$ & $\begin{array}{c}\% \text { of Fund Allocated } \\
\text { to a Sector } \\
\left(S P_{\boldsymbol{i}}=G_{\boldsymbol{i}} \times S M F\right)\end{array}$ & $\begin{array}{c}\text { Amount (Approx.) of } \\
\text { Fund Allocated to } \\
\text { Sector }\left(S F_{\boldsymbol{i}}=\boldsymbol{F} \times S P_{\boldsymbol{i}}\right) \\
\text { (in Rs.) }\end{array}$ \\
\hline 1 & Pharma & 3.1606 & 20.6482 & 20,648 \\
2 & Software & 3.7035 & 24.1949 & 24,195 \\
3 & Petro & 2.7074 & 17.687 & 17,688 \\
4 & Bank & 3.2367 & 21.145 & 21,145 \\
5 & Metal & 2.4977 & 16.3174 & 16,317 \\
\hline
\end{tabular}


In Table 4, we provide the allocation of funds to each company based on their expected returns.

We assume that the allocated funds remain invested throughout the period from 1 January 2021 to 21 May 2021.

We further assume that no stocks were bought or sold during this entire period.

In Table 5, we present the absolute percentage return from each company, which in turn gives us the absolute percentage return from each sector. This table is used for our evaluation and further comparison of performance with popular mutual funds.

Table 4. Allocation of funds within companies.

\begin{tabular}{|c|c|c|c|c|c|c|c|}
\hline Sl. No. & Sector & Company Name & $\begin{array}{l}\text { Sector } \\
\text { Fund }\end{array}$ & $\begin{array}{c}\text { Company } \\
\text { Growth Rate } \\
\left(g_{i}\right)\end{array}$ & CMF & $\begin{array}{l}\% \text { of Sector Fund } \\
\text { Allocated to the } \\
\text { Company } \\
\left(C P_{i}=g_{i} \times C M F\right)\end{array}$ & $\begin{array}{l}\text { Amount of } \\
\text { Fund (in Rs.) } \\
\left(S F_{i} \times C P_{i}\right)\end{array}$ \\
\hline 1 & \multirow{4}{*}{ Pharma } & Dr. Reddy's Lab & \multirow{4}{*}{20,600} & 4.30124 & \multirow{4}{*}{7.8911} & 33.941 & 6992 \\
\hline 2 & & Sun Pharmaceuticals & & 2.6818 & & 21.1629 & 4360 \\
\hline 3 & & Divi's Lab & & 2.1625 & & 17.0650 & 3515 \\
\hline 4 & & Cipla & & 3.5268 & & 27.83 & 5733 \\
\hline 5 & \multirow{4}{*}{ Software } & Infosys & \multirow{4}{*}{24,200} & 4.528 & \multirow{4}{*}{6.7503} & 30.5653 & 7397 \\
\hline 6 & & TCS & & 2.534 & & 17.1052 & 4134 \\
\hline 7 & & HCL & & 3.24 & & 21.87 & 5292 \\
\hline 8 & & Wipro & & 4.512 & & 30.4573 & 7371 \\
\hline 9 & \multirow{4}{*}{ Petro } & Reliance Ind. & \multirow{4}{*}{17,700} & 5.2712 & \multirow{4}{*}{9.2337} & 48.6726 & 8615 \\
\hline 10 & & BPCL & & 2.1074 & & 19.459 & 3444 \\
\hline 11 & & ONGC & & 1.9271 & & 17.795 & 3150 \\
\hline 12 & & Indian Oil Corp. & & 1.524 & & 14.0721 & 2491 \\
\hline 13 & \multirow{4}{*}{ Bank } & HDFC & \multirow{4}{*}{21,100} & 4.109 & \multirow{4}{*}{7.7239} & 31.739 & 6697 \\
\hline 14 & & ICICI & & 2.1034 & & 16.2464 & 3428 \\
\hline 15 & & Kotak Mahindra & & 2.5221 & & 19.48106 & 4111 \\
\hline 16 & & SBI & & 4.212 & & 32.533 & 6864 \\
\hline 17 & \multirow{4}{*}{ Metal } & Hindalco & \multirow{4}{*}{16,300} & 2.014 & \multirow{4}{*}{10.0089} & 20.1579 & 3286 \\
\hline 18 & & SAIL & & 2.84 & & 28.4252 & 4633 \\
\hline 19 & & Tata Steel & & 3.1244 & & 31.2718 & 5097 \\
\hline 20 & & Hindustan Zinc & & 2.0127 & & 20.1449 & 3284 \\
\hline
\end{tabular}

Table 5. Absolute \% return from 1 January to 21 May 2021.

\begin{tabular}{|c|c|c|c|c|c|c|c|}
\hline $\begin{array}{l}\text { Sl. } \\
\text { No. }\end{array}$ & Sector & Company Name & $\begin{array}{l}\text { Closing } \\
\text { Price on } \\
01.01 .2021\end{array}$ & $\begin{array}{l}\text { Closing } \\
\text { Price on } \\
21.05 .2021\end{array}$ & $\begin{array}{l}\text { Absolute \% } \\
\text { Return in } \\
\text { This Period }\end{array}$ & $\begin{array}{l}\text { Return from } \\
\text { Allocated Fund } \\
\text { (in Rs.) }\end{array}$ & $\begin{array}{c}\text { Average } \\
\text { Sector } \\
\text { Absolute \% } \\
\text { Return }\end{array}$ \\
\hline 1 & \multirow{4}{*}{ Pharma } & Dr. Reddy's Lab & 5241.35 & 5216.45 & -0.48 & -34 & \multirow{4}{*}{8.36} \\
\hline 2 & & Sun Pharmaceuticals & 596.25 & 690.4 & 15.79 & 688 & \\
\hline 3 & & Divi's Lab & 3849.05 & 4079.9 & 6 & 211 & \\
\hline 4 & & Cipla & 826.6 & 926.9 & 12.13 & 695 & \\
\hline 5 & \multirow{4}{*}{ Software } & Infosys & 1260.45 & 1354.5 & 7.46 & 552 & \multirow{4}{*}{10.67} \\
\hline 6 & & TCS & 2928.25 & 3080.5 & 5.2 & 215 & \\
\hline 7 & & HCL & 950.5 & 930.65 & -2.09 & -111 & \\
\hline 8 & & Wipro & 388.1 & 512.7 & 32.11 & 2367 & \\
\hline 9 & \multirow{4}{*}{ Petro } & Reliance Ind. & 1987.5 & 2002.55 & 0.76 & 65 & \multirow{4}{*}{14.11} \\
\hline 10 & & BPCL & 381.95 & 461.05 & 20.71 & 713 & \\
\hline 11 & & ONGC & 93.2 & 112.75 & 20.98 & 661 & \\
\hline 12 & & Indian Oil Corp. & 91.5 & 104.3 & 13.99 & 348 & \\
\hline
\end{tabular}


Table 5. Cont.

\begin{tabular}{|c|c|c|c|c|c|c|c|}
\hline $\begin{array}{l}\text { Sl. } \\
\text { No. }\end{array}$ & Sector & Company Name & $\begin{array}{l}\text { Closing } \\
\text { Price on } \\
01.01 .2021\end{array}$ & $\begin{array}{l}\text { Closing } \\
\text { Price on } \\
21.05 .2021\end{array}$ & $\begin{array}{l}\text { Absolute \% } \\
\text { Return in } \\
\text { This Period }\end{array}$ & $\begin{array}{l}\text { Return from } \\
\text { Allocated Fund } \\
\quad \text { (in Rs.) }\end{array}$ & $\begin{array}{c}\text { Average } \\
\text { Sector } \\
\text { Absolute \% } \\
\text { Return }\end{array}$ \\
\hline 13 & \multirow{4}{*}{ Bank } & HDFC & 1425.05 & 1497.3 & 5.07 & 340 & \multirow{4}{*}{14.65} \\
\hline 14 & & ICICI & 527.5 & 642.45 & 21.79 & 747 & \\
\hline 15 & & Kotak Mahindra & 1994.05 & 1757.65 & -11.86 & -488 & \\
\hline 16 & & SBI & 279.4 & 401.2 & 43.59 & 2992 & \\
\hline 17 & \multirow{4}{*}{ Metal } & Hindalco & 238.35 & 389.80 & 63.54 & 2088 & \multirow{4}{*}{61.12} \\
\hline 18 & & SAIL & 74.5 & 122 & 63.76 & 2954 & \\
\hline 19 & & Tata Steel & 643.10 & 1113.10 & 73.08 & 3725 & \\
\hline 20 & & Hindustan Zinc & 239.05 & 344.55 & 44.13 & 1449 & \\
\hline
\end{tabular}

\section{Conclusions}

In conclusion, we compared, quantitatively, the performance of our proposed portfolio with some popular mutual funds that have rendered high returns over the years (presented in Table 6 and Figure 2). The performance data of the mutual funds in the said period were collected from their respective web portals. The absolute percentage return by our proposed portfolio was found to be 21.78 , which is the average of the 'average sector absolute \% return' as given in Table 5.

Table 6. Comparison of the performance of the proposed portfolio with popular mutual funds.

\begin{tabular}{|c|c|c|c|c|c|c|}
\hline Time Period & $\begin{array}{c}\text { Absolute } \\
\text { Return by our } \\
\text { Proposed } \\
\text { Portfolio (\%) }\end{array}$ & $\begin{array}{l}\text { Absolute } \\
\text { Return by } \\
\text { HSBC Large } \\
\text { Cap Equity } \\
\text { Fund Direct } \\
\text { Growth (\%) }\end{array}$ & $\begin{array}{c}\text { Absolute } \\
\text { Return by } \\
\text { ICICI } \\
\text { Prudential } \\
\text { Technology } \\
\text { Direct Growth } \\
\text { (\%) }\end{array}$ & $\begin{array}{c}\text { Absolute } \\
\text { Return by Axis } \\
\text { Bluechip Fund } \\
\text { Direct Plan } \\
\text { Growth (\%) }\end{array}$ & $\begin{array}{c}\text { Absolute } \\
\text { Return by Tata } \\
\text { Digital India } \\
\text { Direct Growth } \\
(\%)\end{array}$ & $\begin{array}{c}\text { Parag Parikh } \\
\text { Flexi Cap Fund } \\
\text { Direct Growth } \\
(\%)\end{array}$ \\
\hline $\begin{array}{l}1 \text { January } 2021 \\
\text { to } 21 \text { May } 2021\end{array}$ & 21.78 & 6.62 & 14.31 & 4.85 & 14.95 & 16.22 \\
\hline
\end{tabular}

We can observe that our proposed portfolio performs quite well during the global pandemic and gives much higher returns as compared to many in-demand mutual funds.

The fact that this research does not cover a longer time frame, such as 3 or 5 years, and the performance is evaluated and compared for only 5 months of investment may be contemplated as a limitation. However, our main idea is that, if this model can sustain in this current global pandemic situation, it has a very high plausibility of sustaining when normalcy is restored. Our experimental results indicate that the proposed portfolio generates higher returns than most of the well-established mutual funds. Although this research was carried out in the context of the Indian stock market, such a sector-wise model and methodology is likely to be compatible with the global market as well since stock markets around the world behaved quite uniformly during this pandemic.

Finally, we can conclude that a well-researched and scientifically generated portfolio is capable of surviving the global pandemic situation and provide better returns, even though the market is very sensitive. It is to be noted that the return could further be maximized by the expert investors if they sold certain shares in their peaks and bought the same at dips. In our experiment, we avoided such practices for simplicity. All the details of the calculation are submitted as supplementary materials. Additionally, it is to be noted that in our proposed portfolio, we did not include any company which deals in alcohol or tobacco products. It is observed that the second wave of COVID-19 was not as damaging as the first wave, as the countries were better prepared this time to counter the situation. It will 
be a very interesting future study to extend this research further by covering a longer time frame to measure the impact of the expected third wave of COVID-19 and also validate this portfolio when normalcy is restored.

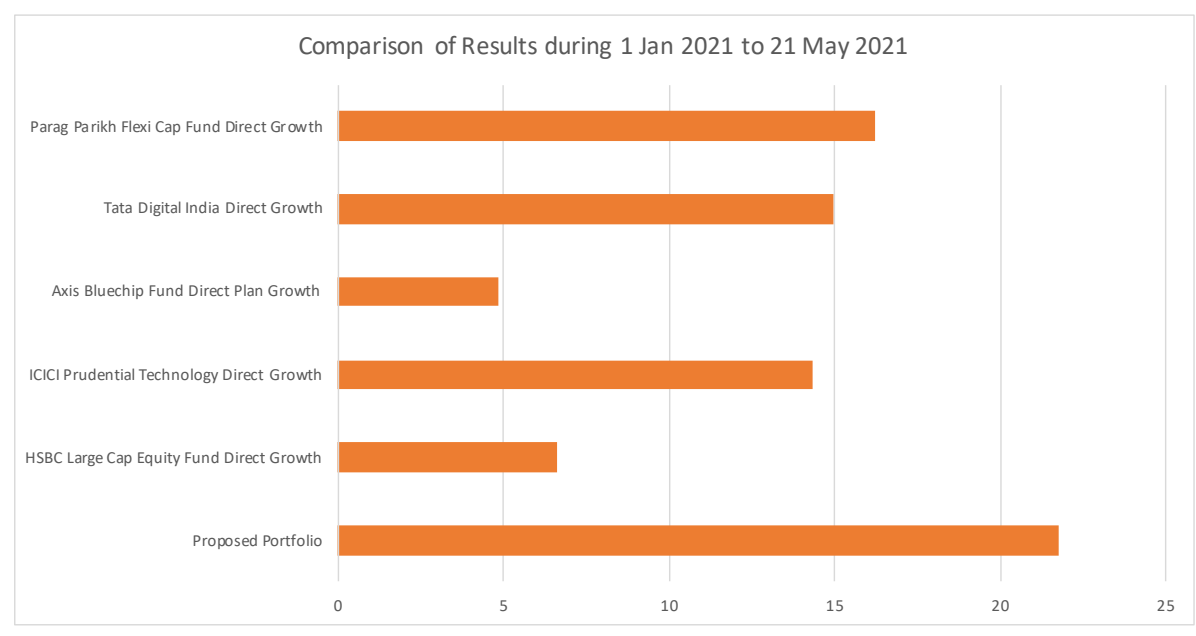

Figure 2. Comparison of the performance of the proposed portfolio with other mutual funds.

Author Contributions: P.D. contributed in conceptualization, investigation, methodology and writing the original draft; H.M.S. contributed in investigation, validation, writing and editing. Both authors have read and agreed to the published version of the manuscript.

Funding: This research received no external funding.

Institutional Review Board Statement: Not applicable.

Informed Consent Statement: Not applicable.

Data Availability Statement: Data used to support the findings of this study are available from Pradip Debnath upon request.

Acknowledgments: The authors express their heartiest gratitude to the learned reviewers for their constructive remarks toward the improvement of the manuscript.

Conflicts of Interest: The authors declare that there has no known competing financial interests or personal relationships with anyone that could have appeared to influence the work reported in this paper.

\section{References}

Al-Awadhi, Abdullah M., Khaled Al-Saifi, Ahmad Al-Awadhi, and Salah Alhamadi. 2020. Death and contagious infectious diseases: Impact of the Covid-19 virus on stock market returns. Journal of Behavioral and Experimental Finance 27: 100326. [CrossRef] [PubMed]

AlArjani, Ali, Md. Maniruzzaman Miah, Md. Sharif Uddin, Abu Hashan Md Mashud, Hui-Ming Wee, Shib Sankar Sana, and Hari Mohan Srivastava. 2021. A sustainable economic recycle quantity model for imperfect production system with shortages. Journal of Risk and Financial Management 14: 173. [CrossRef]

Albulescu, Claudiu Tiberiu. 2020. Covid-19 and the United States' financial market's volatility. Finance Research Letters 38: 101699. [CrossRef] [PubMed]

Altay, Erdinc, and M. Hakan Satman. 2005. Stock market forecasting: Artificial neural network and linear regression comparison in an emerging market. Journal of Financial Management and Analysis 18: 18.

Atsalakis, George S., and Kimon P. Valavanis. 2009. Surveying stock market forecasting techniques: Soft Computing Methods. Expert Systems with Applications 36: 5932-41. [CrossRef]

Baralis, Elena, Luca Cagliero, and Paolo Garza. 2017. Planning stock portfolios by means of weighted frequent itemsets. Expert Systems with Applications 86: 1-17. [CrossRef]

Dou, Winston, Yan Ji, David J. Reibstein, and Wei Wu. 2021. Inalienable customer capital, corporate liquidity, and stock returns. The Journal of Finance 76: 211-65. [CrossRef] 
Engelhardt, Nils, Miguel Krause, Daniel Neukirchen, and Peter Posch. 2020. What drives stocks during the Corona-crash? News attention vs. rational expectation. Sustainability 12: 5014. [CrossRef]

Erdem, Orhan. 2020. Freedom and stock market performance during covid-19 outbreak. Finance Research Letters 36: 101671. [CrossRef] [PubMed]

Gottschlich, Jorg, and Oliver Hinz. 2014. A decision support system for stock investment recommendations using collective wisdom. Decision Support Systems 59: 52-62. [CrossRef]

Liao, Shu-Hsien, Pei-Hui Chu, and Pei-Yuan Hsiao. 2012. Data mining techniques and applications-A decade review from 2000 to 2011. Expert Systems with Applications 39: 11303-11. [CrossRef]

Maji, Giridhar, Debomita Mondal, Nilanjan Dey, Narayan C. Debnath, and Soumya Sen. 2021. Stock prediction and mutual fund portfolio management using curve fitting techniques. Journal of Ambient Intelligence and Humanized Computing. [CrossRef] [PubMed]

Mazur, Mieszzko, Man Dang, and Miguel Vega. 2020. COVID-19 and the march 2020 stock market crash. Evidence from S\&P1500. Finance Research Letters 38: 101690. [CrossRef] [PubMed]

Paranjape-Voditel, Preeti, and Umesh Deshpande. 2013. A stock market portfolio recommender system based on association rule mining. Applied Soft Computing 13:1055-63. [CrossRef]

Rahman, Md Lutfur, Abu S. Amin, and Mohammed Abdullah Al Mamun. 2021. The COVID-19 outbreak and stock market reactions: Evidence from Australia. Finance Research Letters 38: 101832. [CrossRef]

Rusu, Virginia, and Cristian Rusu. 2003. Forecasting methods and stock market analysis. Creative Mathematics 12: 103-10.

Takahashi, Hidenori, and Kazuo Yamada. 2020. When Japanese stock market meets Covid-19. Impact of ownership, trading, esg, and liquidity channels. SSRN Electronic Journal. [CrossRef]

Wilms, Ines, Jeroen Rombouts, and Christophe Croux. 2021. Multivariate volatility forecasts for stock market indices. International Journal of Forecasting 37: 484-99. [CrossRef]

Zaremba, Adam, Renatas Kizys, David Y. Aharon, and Ender Demir. 2020. Infected Markets: Novel coronavirus, Government interventions, and stock return volatility around the globe. Finance Research Letters 35: 101597. [CrossRef] [PubMed]

Zhang, Dayong, Min Hu, and Qiang Ji. 2020. Financial markets under the global pandemic of COVID-19. Finance Research Letters 36: 101528. [CrossRef] [PubMed] 